\title{
Correspondence
}

Contents: Psychiatry and the concept of evil/OGS or tardive dystonia?/Huntington's disease in the Oxford region/Anaesthetic technique in the practice of ECT/Counselling and community psychiatric nurses/Home- v. hospital-based care for people with serious mental illness/Investigating multiple personality disorder/A spiritual dimension to mental illness

\section{Psychiatry and the concept of evil}

SIR: The editorial by Prins and the comment by His Hon. Judge Jones (BJP, September 1994, 165, 297-302) was of great interest and I found myself at one with Judge Jones in accepting the notion of there being "evil/sane people", "good/sane people" and "good/mentally ill people" but I am rather less certain about a fourth category of "evil/mentally ill people". My uncertainty regarding the category of "evil/mentally ill people" causes me to consider the matter of what is a mental illness.

I am somewhat surprised that neither Prins or Jones advert to the concept of "psychopathy" or "psychopathic disorder" or the "personality disorders" (there are eleven subgroups noted in DSM-IV).

In this State (Victoria) the diagnosis of a personality disorder has been deemed to be not a mental illness or someone being mentally ill. This state of affairs has not arisen in relation to legislation but is due to a finding by the Mental Health Review Board (Mental Health Act (Vict.) 1986 ss $21-46$ in a case of Attorney-General v. David [1992] 2 V.R. 46-96, and Kiel, 1992). The finding in the case of David relates to all personality disorders including the antisocial and borderline states. The position in England and Wales seems to differ - not only are the various conditions seen as mental illnesses but will allow of certification in appropriate cases, whereas in Victoria extra-ordinary legislation was passed in order to deal with the notion of dangerousness (Bartholomew, 1992).

If personality disorder is not an illness then much "evil" behaviour will not be an illness and so remain designated as being "evil/sane people"; this in Victoria but not in England and Wales. The problem for the psychiatrist is to attempt to disentangle "evil" from "illness" and this is the task which Jones quite properly hands to the psychiatrist. It is right and proper that the psychiatrist may research the question "Is this person mentally ill?" and if such person is mentally ill ask the further question "How can I treat this person?". But what if there is an untreatable illness. Is it appropriate to incarcerate in terms of "care"?

BArtholomew, A. A. (1992) Dangerousness: A Novel Approach. Psychiatric Bulletin, 16, 299-300.

KIEL, H. (Ed.) (1992) Decisions of the Mental Health Review Board Victoria 1987-1991. Melbourne (1992), Cases 20, 21 pp. 147-159-207 Both cases were "Appeals".

Suite 1, 8th Floor

A. BARTHOLOMEW

118 Queen Street

Melbourne 3000

SIR: In matters of evil and of distinguishing madness and badness, Prins and Jones (BJP, September $1994,165,297-302)$ agree with the old rhyme's dictum that "doctors should attend the sick and leave the well alone". Or in this case, that we should leave the evil-well to other professions.

But no specialism, science or profession is an island. Medicine employs its science in the greater cause of helping and healing. To heal the sick especially where mental healing is our speciality and there is an IC "Disease" diagnostic category for almost everything that moves - requires a knowledge of well-functioning, and expertise that enables a person's return to it. Sickness is only a part of the whole situation we work with. The wider context of the future and of a knowledge of healthy functioning - is an integral part of our immediate attention to the unhealthy.

In legal contexts, the psychiatrist's required preoccupation may be with the adult legal question of the accused's knowing the difference between right and wrong. This may be basic to the pursuit of justice. But it creates considerable difficulties in that it is also a partial matter that prevents us addressing the whole situation, including a contribution to 